\title{
The two faces of nanomaterials: A quantification of hormesis in algae and plants
}

\author{
Evgenios Agathokleous $^{\mathrm{a}, *}$, ZhaoZhong Feng ${ }^{\mathrm{a}}$, Ivo Iavicoli ${ }^{\mathrm{b}}$, Edward J. Calabrese \\ ${ }^{a}$ Institute of Ecology, Key Laboratory of Agrometeorology of Jiangsu Province, School of Applied Meteorology, Nanjing University of Information Science \& Technology, \\ Nanjing 210044, China \\ ${ }^{\mathrm{b}}$ Department of Public Health, University of Naples Federico II, 80131 Naples, Italy \\ ${ }^{\mathrm{c}}$ Department of Environmental Health Sciences, Morrill I, N344, University of Massachusetts, Amherst, MA 01003, USA
}

\section{A R T I C L E I N F O}

Handling Editor: Olga-Ioanna Kalantzi

\section{Keywords:}

Agricultural sustainability

Environmental pollution

Hormesis

Nanoparticles

Preconditioning

Priming

\begin{abstract}
A B S T R A C T
The rapid progress in nanotechnology has dramatically promoted the application of engineered nanomaterials in numerous sectors. The wide application of nanomaterials and the potential accumulation in the environment sparked interest in studying the effects of nanomaterials on algae and plants. Hormesis is a dose response phenomenon characterized by a biphasic dose response with a low dose stimulation and a high dose inhibition. This paper quantifies for the first time nanomaterial-induced hormesis in algae and plants. Five hundred hormetic concentration-response relationships were mined from the published literature. The median maximum stimulatory response (MAX) was $123 \%$, and commonly below $200 \%$, of control response. It was also lower in algae than in plants, and occurred commonly at concentrations $<100 \mathrm{mg} \mathrm{L}^{-1}$. The no-observed-adverse-effectlevel (NOAEL) to MAX ratio was 2.4 for algae and 1.7 for plants, and the two distributions differed significantly. Ag nanoparticles induced higher MAX than $\mathrm{TiO}_{2}$ and $\mathrm{ZnO}$ nanoparticles. The MAX varied upon nanomaterial application methods, growth stage of application (seed versus vegetative), type of endpoint and time window. While nanomaterial size did not affect significantly the MAX, sizes $\leq 50 \mathrm{~nm}$ appeared to have lower NOAEL:MAX ratio than sizes $\geq 100 \mathrm{~nm}$, suggesting higher risks from incorrect application. The mechanisms underlying nanomaterial-induced hormetic concentration responses are discussed. This paper provides a strong foundation for enhancing research protocols of studies on nanomaterial effects on algae and plants as well as for incorporating hormesis into the risk assessment practices.
\end{abstract}

\section{Introduction}

The wide expansion of nanotechnology and the thereby application of engineered nanomaterials in industrial and agricultural sectors lead to the accumulation of nanomaterials in the environment, stimulating the need to understand how plants and algae respond to nanomaterials, and what the implications in agriculture and ecological and human health may be (Auta et al., 2017; Carbery et al., 2018; Freixa et al., 2018; Iavicoli et al., 2017; Kabir et al., 2018; Navarro et al., 2008). For these reasons, research on plant responses to nanomaterials has received heightened interest in the recent years (Chen et al., 2018; Kumar et al., 2019; Rai et al., 2018; Verma et al., 2018, 2019). While there has been much focus on the adverse/toxic effects of high loads of engineered nanomaterials on plants, empirical data have now accumulated showing that low loads of engineered nanomaterials $(<50 \mathrm{mg}$ $\mathrm{kg}^{-1}$ ) usually induce positive/stimulatory effects on plants (Cota-Ruiz et al., 2018; Rai et al., 2018; Reddy et al., 2016; Reddy Pullagurala et al., 2018), hinting to hormesis (Fig. 1).

Hormesis is a dose response phenomenon characterized by a biphasic dose response with a low dose stimulation and a high dose inhibition (Calabrese, 2014). Hormesis induced in plants and algae would have implications in different sectors such as research (e.g. experimental designs and study of biological mechanisms), agriculture (enhancing plant yield and productivity), environment (ecological

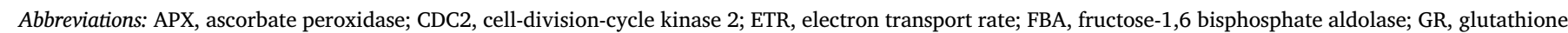

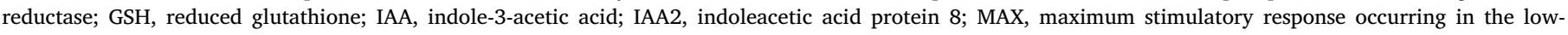

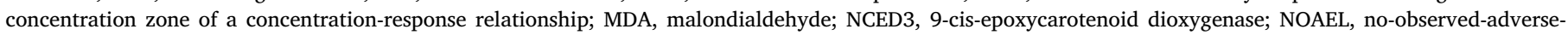

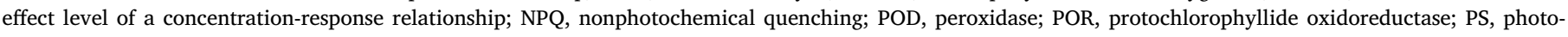
system; qP, plastoquinone pool; ROS, reactive oxygen species; SOD, superoxide dismutase

* Corresponding author.

E-mail address: evgenios@nuist.edu.cn (E. Agathokleous). 


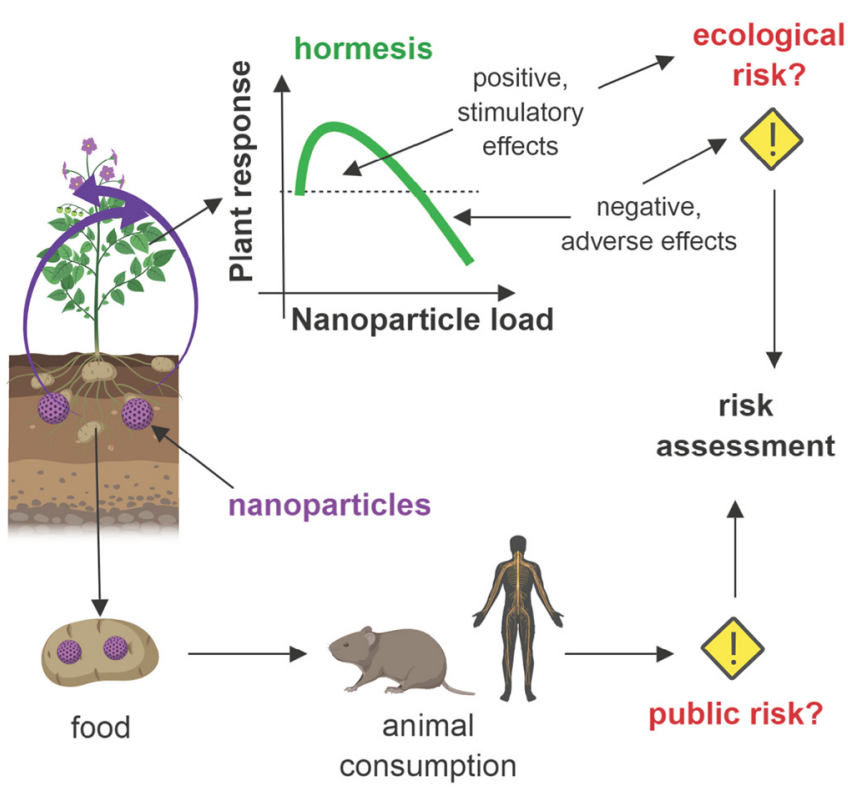

Fig. 1. Schematic diagram illustrating the issue of nanoparticles accumulation in the environment (or direct application to plants by humans), along with nanoparticles effects in a hormetic context, and the potential risks. The figure was created with the help of Biorender (credits: E. Agathokleous).

impacts), and human and ecological risk assessment (toxicological estimates) (Agathokleous et al., 2019b; Agathokleous and Calabrese, 2019; Belz and Duke, 2017; Cutler and Guedes, 2017; Cutler and Rix, 2015; Iavicoli et al., 2018; Poschenrieder et al., 2013). Hence, in the light of the continuous and increasing use and application of nanotechnology across the globe, understanding dose-response relationships induced by nanomaterials in plants and algae has emerged as an important issue in nano-toxicological research (Iavicoli et al., 2018). This is particularly important since nanomaterials may often occur at trace to low concentrations in the environment (Sanchís et al., 2012a,b), urging for advancing the understanding of the low-concentration effects.

For the first time, this study documents, evaluates and discusses hormetic concentration-response relationships induced by nanomaterials in plants and algae in the context of source-exposure-health outcome continuum.

\section{Documentation}

Evidence for nanomaterials-induced hormesis in plants existed from the mid-2000s (Hong et al., 2005; Lin and Xing, 2007; Zheng et al., 2005). However, hormesis, with typical biphasic concentration-response relationship, was first reported in 2010, when root elongation was assessed in plants of rape (Brassica napus L.) after treatment with rare earth oxide nanoparticles $\left(\mathrm{La}_{2} \mathrm{O}_{3}\right.$ and $\left.\mathrm{Yb}_{2} \mathrm{O}_{3}\right)$ (Ma et al., 2010), and for algae, when growth rate of a freshwater green alga (Pseudokirchneriella subcapitata) was assessed after exposure to titanium dioxide $\left(\mathrm{TiO}_{2}\right)$ particles (Hartmann et al., 2010). The first review study focusing on nanoparticle-induced hormesis in different biological models revealed limited evidence for hormesis, and this was notable for both plants and algae (Iavicoli et al., 2010). This was also the case for a later review study, but with more evidence for green algae (Iavicoli et al., 2014); however, the increase in the interest in the research field and the improved research protocols noted in the recent years revealed more studies ( $n=8$ for plants, $n=2$ for algae) with evidence for hormesis induced by nanoparticles (Iavicoli et al., 2018).

The studies cited in the previous reviews (Iavicoli et al., 2010, 2014, 2018) were re-evaluated for the existence of hormetic concentrationresponse relationships. A concentration-response relationship was

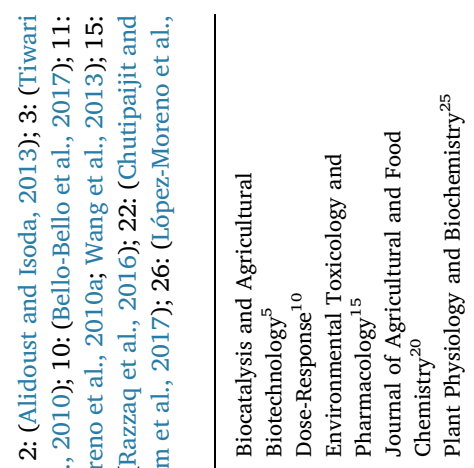


classified hormetic if there was a stimulatory response to at least one exposure level ( $>100 \%$ of control) followed by a decline in the response, thus, presenting a biphasic concentration-response relationship. This literature sample was significantly enriched by surveying additional studies, after reviewing the published literature for existence of hormetic concentration-response relationships in plants and algae based on the aforementioned criterion. This effort resulted to the identification of a sample of 9 papers with algae and 31 papers with plants (tracheophytes) reporting data documenting hormetic concentration-response relationships. These studies often incorporated multi-factorial experimental designs including different species or different types or sizes of nanoparticles. The 40 papers were published from 2005 to 2019, in 29 journals with a broad range of scopes and aims; $50 \%$ of these papers were published in the last 3 years (post 2015), indicating an increased interest and more robust experimental designs permitting the detection of hormesis (Table 1 ).

\section{Evaluation}

To evaluate nanomaterials-induced hormetic concentration-response relationships quantitatively, data were extracted from tables or figures (Adobe Photoshop CS4 Extended v.11, Adobe Systems Incorporated, CA, USA) of the 40 papers. The response to nanomaterial treatment (\% of control response; control is commonly a null exposure) was calculated as Response $=\mu_{C} / \mu_{\chi} \times 100$, where $\mu_{\mathrm{c}}$ is the arithmetic mean of the control group and $\mu_{\chi}$ is the arithmetic mean of a group treated with a nanomaterial concentration level of $\chi$. ${ }^{1}$ For endpoints where a decrease in the response can have biologically positive effect (e.g. reduction of reactive oxygen species, ROS, and malondialdehyde, MDA), the response was calculated as Response $=\mu_{\chi} / \mu_{c} \times 100$.

This evaluation yielded 499 concentration responses (46 with algae and 453 with plants) with maximum stimulatory response (MAX). These were induced by 29 unique nanomaterials (Supplementary materials, Section 1) in at least 5 algae taxa (one species unidentified) and 20 plant taxa. A qualitative assessment of the experiments to depict hormesis revealed a low score for strength (3.0 for algae and 7.5 for plants; Supplementary materials, Section 2), which is however higher than other hormesis databases with plants (Agathokleous et al., 2019a). Concentration-response relationships were developed, and the no-observed-adverse-effect level (NOAEL) was estimated. Since not all the concentration responses crossed the zero equivalent point (ZEP), the distance from MAX to NOAEL (NOAEL:MAX ratio) could be estimated (Adobe Photoshop CS4 Extended v.11, Adobe Systems Incorporated, CA, USA) for 269 entries (of which 39 were from algae).

The median MAX for all the concentration responses was $122.8 \%$ (geometric mean $=137.3 \%$ ) and lower in algae than in plants (Table 2). The NOAEL:MAX ratio (median $=1.8$, geometric mean $=2.2$ ), was 1.4 times higher in algae than in plants (Table 2). Although the sample size for algae is small for drawing robust conclusions (given the complexity of nanomaterial effects), these results may suggest that algae may have a lower MAX response but with a wider stimulatory zone than plants. The 487 concentration responses displayed a MAX commonly ( $90.0 \%$ ) below $200 \%$ of the control response: $41.1 \%$ showed a MAX in the range $[110 \%-150 \%$ ) while $22.2 \%$ showed a MAX in the range [150\%-200\%); excluding algae, the percentages were $91.4 \% \quad(<200 \%), \quad 39.1 \% \quad[110 \%-150 \%)$ and $23.4 \%$ [150\%-200\%). The frequency of MAX occurrence below $200 \%$ of control response is similar to previous analyses where a variety of stress inducing agents induced hormesis in plants (Agathokleous et al., 2019a; Calabrese and Blain, 2009).

Excluding algae (and 20 entries concerning calli), the plant entries

\footnotetext{
${ }^{1}$ Note: For several concentration-response relationships in (Zheng et al., 2005), the units of the endpoints were not given and thus the response could not be calculated (those data are excluded from this analysis).
}

Table 2

Hormesis characteristics for algae and plants. Analysis of the median maximum stimulatory response (MAX) and the median distance from MAX to no-observed-adverse-effect level (NOAEL) (NOAEL:MAX ratio). The level of significance was set a priori to $\alpha=0.05$. All the analyses in this study were conducted with MS EXCEL 2010 (Microsoft(C) and STATISTICA v.10 (StatSoft Inc.(C).

\begin{tabular}{lll}
\hline & MAX & NOAEL:MAX ratio \\
\hline Algae & $119.7 \%(n=46)$ & $2.4(n=39)$ \\
Plants & $125.2 \%(n=453)$ & $1.7(n=229)$ \\
Kruskal-Wallis test & $H=4.00, P=0.046$ & $H=6.32, P=0.012$ \\
\hline
\end{tabular}

were grouped into those where treatment was done only at the stage of seed (seed soaking, $n=64$ ) and those where treatment was classically done during plant growth (vegetative stage, $n=369$ ). An analysis revealed a significant difference in the MAX (Kruskal-Wallis, $H=4.48$, $P=0.34$ ) between seed soaking (median $=147.1 \%$, geometric mean $=150.3 \%$ ) and vegetative stage (median $=122.6 \%$, geometric mean $=137.0 \%)$. Although the sample size for seed soaking is not large, these findings suggest that: a) seed soaking with nanoparticles can effectively induce MAX; b) treatment of seed with nanoparticles may be seen as a potential medium for seed priming; and c) combination of seed soaking and application during vegetative stages may offer an optimum stimulation.

Plant entries were also categorized as to the tissue from which nanoparticles are taken up, i.e. roots $(n=267)$ versus foliage $(n=144)^{2}$ (excluding calli-regenerated plants). The median for roots was $127.3 \%$ (geometric mean $=140.4 \%$ ) whereas for foliage was $114.9 \%$ (geometric mean $=126.7 \%$ ), and the two distributions differed significantly (Kruskal-Wallis, $H=11.79, P<0.001$ ). While nanoparticles may enter the tree stem faster when applied to leaves than when applied to roots (Cocozza et al., 2019), this analysis revealed that applying nanoparticles onto leaves does not necessarily yield higher MAX. Further, the root entries were grouped into two categories: a) those with plants grown in a liquid growing medium (hydroponic system, $n=88$ ) and b) those with plants grown in soil substrate (no hydroponic system, $n=179$ ). The median MAX values were 125.5 and $128.8 \%$ for hydroponic and no hydroponic systems (geometric means of 132.9 and $144.2 \%)$. The similar distribution of the two groups (Kruskal-Wallis, $H=0.05, P=0.832$ ) suggests that application of nanoparticles into a soilless growing medium can induce similar MAX as when applied onto soil. This suggestion is supported by an experiment where phosfon-induced hormesis in peppermint (Mentha piperita) plants was similar either in a soil medium or a mineral nutrient solution (Calabrese and Howe, 1976). Hence, nanoparticles can be used within a hormetic context in greenhouse hydroponic cultures too (Venkatachalam et al., 2017). This finding also suggests that soil-particles interaction is not a major driver of hormesis.

The size of the nanomaterials did not appear to influence significantly the MAX (Table 3A). However, the NOAEL:MAX increased considerably when the particles increased in size from $\leq 50 \mathrm{~nm}$ to $>$ $100 \mathrm{~nm}$ (Table 3B). These results suggest that ultrafine particles $(<50 \mathrm{~nm})$ are less "safe" than fine particles $(>100 \mathrm{~nm})^{3}$ because they may generate higher environmental/ecological risk due to the smaller concentration range separating MAX from NOAEL (after which adverse effects are expected to begin). While this analysis does not incorporate bulk particles and the entries with particle size $>300 \mathrm{~nm}$ are limited, some difference may exist between fine and bulk particles. For instance, when tested at the same concentrations, ultra-fine particles $(<150 \mathrm{~nm})$ seem to have a higher capacity to induce hormesis with low-

\footnotetext{
${ }^{2}$ In some studies the application method was not given.

${ }^{3}$ Particles are classified ultrafine, fine and coarse when their size is $1-100$, 100-2500 and 2500-10,000 nm, respectively.
} 
Table 3

Hormesis dependence on nanoparticle size in algae and plants. Analysis of the median maximum stimulatory response (MAX) and the median distance from MAX to no-observed-adverse-effect level (NOAEL) (NOAEL:MAX ratio). Different lowercase letters above medians indicate significant differences for groups with one or more samples stochastically dominating another sample after applying a Bonferroni correction against inflation of Type I error. Different uppercase letters above medians indicate significant differences with no applying a Bonferroni correction against inflation of Type I error $(\alpha=0.05)$.

\begin{tabular}{llll}
\hline Particle size & Median (\%) & $\begin{array}{l}\text { Geometric } \\
\text { mean (\%) }\end{array}$ & $\begin{array}{l}\text { Sample size (number of } \\
\text { concentration } \\
\text { responses) }\end{array}$ \\
\hline A) MAX & & & \\
$\leq 10$ & 122.2 & 133.4 & 121 \\
$>10 \leq 20$ & 121.2 & 135.4 & 260 \\
$>20 \leq 50$ & 138.9 & 142.0 & 55 \\
$\geq 100 \leq 380$ & 121.9 & 138.2 & 35 \\
Kruskal-Wallis test & $H=5.31$, & & \\
& $P=0.150$ & & \\
B) NOAEL:MAX & & & \\
$\leq 10$ & $1.7^{\mathrm{aAB}}$ & 2.1 & 46 \\
$>10 \leq 20$ & $1.6^{\mathrm{aA}}$ & 1.9 & 43 \\
$>20 \leq 50$ & $1.9^{\mathrm{abC}}$ & 2,6 & 19 \\
$\geq 100 \leq 380$ & $3.0^{\mathrm{bC}}$ & 4.0 & \\
Kruskal-Wallis test & $H=22.93$, & & \\
& $P<0.001$ & & \\
\hline
\end{tabular}

Note: the size of the nanoparticles was not reported in all the papers.

concentration stimulation and higher toxicity at high concentrations than bulk/fine particles (> $300 \mathrm{~nm}$ ) (Ji et al., 2011; Warheit et al., 2007). This may be because nanoparticles may have a higher potential to adsorb onto soil colloids, than bulk particles of the same material, because of their high large surface area to mass ratio (Alidoust and Isoda, 2014).

Other factors may influence the concentration-response relationships such as particle aggregation, heteroaggregation, aggregate structure, shape, surface functionalization, crystallinity, metal concentration and stabilizer (Supplementary materials, Section 3) (Hartmann et al., 2010; Ma et al., 2010; Syu et al., 2014; Wang et al., 2013; Bello-Bello et al., 2018). However, presently the available literature does not permit such an evaluation.

From the 478 entries, 422 (of which only 14 for algae) reported concentrations in $\mathrm{mg} \mathrm{L}^{-1}$ or in units that permitted conversion to $\mathrm{mg}$ $\mathrm{L}^{-1}$. The median concentration inducing MAX was $30.0 \mathrm{mg} \mathrm{L}^{-1}$ (geometric mean $=40.3 \mathrm{mg} \mathrm{L}^{-1}$ ). A breakdown of the concentrations induced MAX reveals that 58.8 or $73.5 \%$ of these entries displayed MAX at concentrations $\leq 50$ or $\leq 100 \mathrm{mg} \mathrm{L}^{-1}$, suggesting that MAX appears commonly at concentrations $\leq 100 \mathrm{mg} \mathrm{L}^{-1}$ (Fig. 2). To test whether MAX depends on the inducing concentration, the 422 entries were

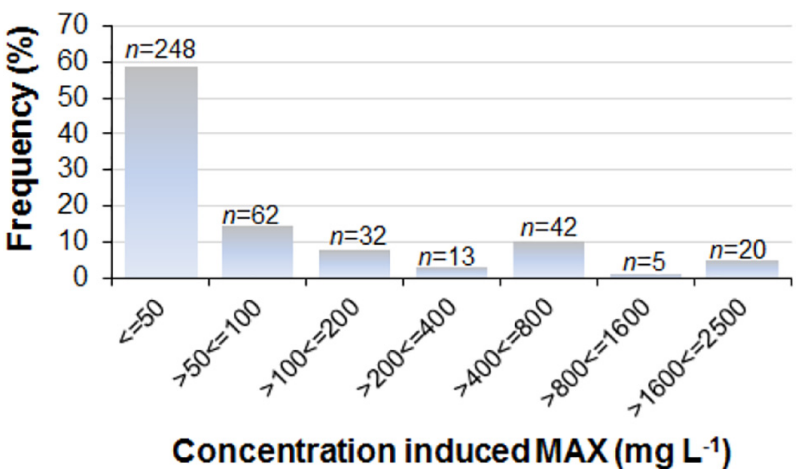

Fig. 2. Concentrations induced maximum stimulatory response (MAX) in algae $(n=14)$ and plants $(n=408)$. The frequency indicates the percentage of 422 dose responses. High concentrations $>400 \mathrm{mg} \mathrm{L}^{-1}$ where commonly from experiments with seed soaking (see Table 5).
Table 4

Dependence of the maximum stimulatory response (MAX) on the inducing concentration in algae and plants. Different lower case letters above medians indicate significant differences for groups with one or more samples stochastically dominating another sample after applying a Bonferroni correction against inflation of Type I error. Different uppercase letters above medians indicate significant differences with no applying a Bonferroni correction against inflation of Type I error ( $\alpha=0.05)$.

\begin{tabular}{lll}
\hline $\begin{array}{l}\text { Concentrations induced MAX } \\
\left(\mathrm{mg} \mathrm{L}^{-1}\right)\end{array}$ & $\begin{array}{l}\text { Number of concentration } \\
\text { responses }\end{array}$ & Median MAX (\%) \\
\hline$\leq 10$ & 88 & $119.7^{\mathrm{aAB}}$ \\
$\geq 15 \leq 25$ & 74 & $113.0^{\mathrm{aA}}$ \\
$\geq 30 \leq 50$ & 86 & $155.5^{\mathrm{bC}}$ \\
$\geq 60 \leq 125$ & 72 & $130.4 \mathrm{~b}^{\mathrm{abBC}}$ \\
$\geq 200$ & 102 & $124.9^{\mathrm{abAB}}$ \\
Kruskal-Wallis test & $H=27.21, P<0.001$ & \\
\hline
\end{tabular}

grouped based on the range of concentrations, such that the groups provide a sufficient sample size of concentration responses and independent studies (Table 4). This analysis revealed that the maximum median MAX (across any other experimental conditions) increased when the MAX-induced concentrations increased up to $30-50 \mathrm{mg} \mathrm{L}^{-1}$, suggesting that concentrations below $30 \mathrm{mg} \mathrm{L}^{-1}$ may be inadequate to induce a MAX closer to the real one; concentrations above $50 \mathrm{mg} \mathrm{L}^{-1}$ may also underestimate the real MAX which may be due to chemical engineering factors (e.g. chemical aggregation).

The plant entries with concentration in $\mathrm{mg} \mathrm{L}^{-1}$ were further analyzed (20 entries with calli were excluded) between those where treatment was done only at the stage of seed (seed soaking) and those where treatment was classically done during plant growth (vegetative stage). The distributions of the two groups differed significantly (Table 5), with the median MAX-inducing concentration being 21.7 times higher at seed stage than at vegetative stage. Given that the NOAEL:MAX ratio for plants is $<2$, it seems that seed stage has multifold plastic limits than vegetative stages. However, seed size may define how seeds respond to nanomaterials. For instance, small seeds have higher surface to volume ratio than large seeds, thus, higher responses at lower concentrations may occur in small seeds (Ma et al., 2010), something that should be considered in the future.

Among the nanomaterials used, only three groups could be created to provide a robust sample size for analysis, i.e. Ag (excluding 16 entries with carbon- and PEG-coated $\mathrm{Ag}$ ), $\mathrm{TiO}_{2}, \mathrm{ZnO}$. $\mathrm{Ag}$ induced higher median MAX than $\mathrm{TiO}_{2}$ and $\mathrm{ZnO}$, although at a less strict alpha level $(P=0.044)$ for $\mathrm{TiO}_{2}$ (Table 6), suggesting that the elemental release from particles is not the major reason for stimulation or that silver may simultaneously suppress fungi with these plants showing a higher MAX. In a further analysis, the dose responses were grouped into those induced by nanomaterials containing essential elements ( $\mathrm{N}, \mathrm{P}, \mathrm{K}, \mathrm{Ca}, \mathrm{Mg}$, $\mathrm{S}, \mathrm{B}, \mathrm{Cl}, \mathrm{Fe}, \mathrm{Mn}, \mathrm{Zn}, \mathrm{Cu}, \mathrm{Mo}, \mathrm{Ni}, \mathrm{H}, \mathrm{O}$ and $\mathrm{C}$ ) and those containing only non-essential elements. Interestingly, the median MAX was higher for the group of non-essential elements than the group of the essential elements, and the two distributions differed significantly (Table 6). These findings suggest that the MAX is not upon essential elements of the nanoparticles but also that incorporation of essential elements in the nanomaterials may yield lower MAX (e.g. it may reduce the "xenobiotic effect").

Hormesis seems to depend on the type of nanomaterials, with different nanomaterials displaying different responses at the same concentrations, when tested under same experimental conditions (Alidoust and Isoda, 2014; Chutipaijit and Sutjaritvorakul, 2017; Huang et al., 2018; López-Moreno et al., 2010a; Ma et al., 2010), and our analysis may support this hypothesis. Mixtures of nanoparticles can also induce hormesis (Taran et al., 2016), and more experiments are needed to provide insights important for risk assessment in the future.

The concentration responses, for which the time window from 
Table 5

Analysis of the median maximum stimulatory response (MAX) as per the plant growth stage. The level of significance was set a priori to $\alpha=0.05$.

\begin{tabular}{|c|c|c|}
\hline Concentrations induced MAX $\left(\mathrm{mg} \mathrm{L}^{-1}\right)$ & Number of concentration responses & Median MAX-inducing concentration $\left(\mathrm{mg} \mathrm{L}^{-1}\right)$ \\
\hline Seed stage & 64 & 650.0 \\
\hline Vegetative stage & 324 & 30.0 \\
\hline Kruskal-Wallis test & $H=19.98, P<0.001$ & \\
\hline
\end{tabular}

Table 6

Dependence of the maximum stimulatory response (MAX) on the type of nanomaterial. Different lower case letters above medians indicate significant differences for groups with one or more samples stochastically dominating another sample after applying a Bonferroni correction against inflation of Type I error. Different uppercase letters above medians indicate significant differences with no applying a Bonferroni correction against inflation of Type I error $(\alpha=0.05)$.

\begin{tabular}{lll}
\hline Nanomaterial & $\begin{array}{l}\text { Number of concentration } \\
\text { responses }\end{array}$ & $\begin{array}{l}\text { Median MAX } \\
(\%)\end{array}$ \\
\hline $\mathrm{Ag}$ & 79 & $161.0^{\mathrm{bB}}$ \\
$\mathrm{TiO}_{2}$ & 42 & $135.1^{\mathrm{abA}}$ \\
$\mathrm{ZnO}$ & 100 & $123.5^{\mathrm{aA}}$ \\
Kruskal-Wallis test & $H=18.80, P<0.001$ & $117.1^{\mathrm{aA}}$ \\
Including essential elements & 338 & $146.1^{\mathrm{bB}}$ \\
$\begin{array}{l}\text { Including only non-essential } \\
\quad \text { elements }\end{array}$ & 161 & \\
$\quad$ & $H=38.44, P<0.001$ & \\
\hline
\end{tabular}

\section{Table 7}

Dependence of the maximum stimulatory response (MAX) on the time window. Different letters above medians for NOAEL:MAX indicate significant differences for groups with one or more samples stochastically dominating another sample (after applying a Bonferroni correction against inflation of Type I error). The level of significance was set a priori to $\alpha=0.05$.

\begin{tabular}{lll}
\hline Time (days) & Number of concentration responses & Median MAX (\%) \\
\hline$\leq 14$ & 206 & $116.0^{\mathrm{a}}$ \\
$>14 \leq 30$ & 138 & $151.3^{\mathrm{c}}$ \\
$>30 \leq 90$ & 153 & $125.7^{\mathrm{b}}$ \\
Kruskal-Wallis test & $H=30.46, P<0.001$ & \\
\hline
\end{tabular}

treatment to response measurement was given or could be calculated, could be grouped into three robust groups, i.e. $\leq 14,>14 \leq 30$ and $>30$ days. Interestingly, it seems that MAX was maximized in 15-30 days and then dropped to a lower level again (Table 7). A recent analysis of lanthanum effects on plants also suggested that MAX may decline over time but can still remain at a biologically important level (i.e. $>120 \%$ ) to offer a net benefit (Agathokleous et al., 2019c). This is the case for nanomaterials where even if the median MAX declines after 1 month it still remains at a biologically important level (126\%).

The major types of endpoints for the 499 concentration responses were biochemical (34.1\%), growth (16.4\%), physiological (11.4\%) and production (20.6\%). The lowest median MAX appeared for physiological endpoints (Table 8), and this might be explained by the high temporal variation of physiological endpoints (in addition to the small sample size) which is commonly not accounted for in the experiments (i.e. MAX may be measured at a time where response is not at the maximum). The distribution of production endpoints (including yields and biomasses) was significantly different for those of growth and physiological but not that of chemical endpoints. The higher medians for production and biochemical endpoints might be due to the possibility that they are less influenced by the temporal component than physiological endpoints.

\section{Mechanisms}

The herein evaluation suggests that nanomaterial-induced hormesis
Table 8

The maximum stimulatory response (MAX) as per the major types of endpoints. Different lowercase letters above medians indicate significant differences for groups with one or more samples stochastically dominating another sample after applying a Bonferroni correction against inflation of Type I error. Different uppercase letters above medians indicate significant differences with no applying a Bonferroni correction against inflation of Type I error $(\alpha=0.05)$.

\begin{tabular}{lll}
\hline Type of endpoint & Number of concentration responses & Median MAX (\%) \\
\hline Biochemical & 170 & $123.0^{\mathrm{bcBC}}$ \\
Growth & 82 & $121.8^{\mathrm{abB}}$ \\
Physiological & 57 & $110.3^{\mathrm{aA}}$ \\
Production & 103 & $141.2^{\mathrm{cC}}$ \\
Kruskal-Wallis test & $H=37.13, P<0.001$ & \\
\hline
\end{tabular}

is not an outlier phenomenon but rather a widely occurring and well documented one. Hence, these understandings should be supported by a mechanistic basis.

\subsection{Preconditioning or not?}

Nanomaterials can change the response of plants and algae to other stressors, such as heavy metals (Hartmann et al., 2010; Huang et al., 2018), indicating that nanomaterials can induce preconditioning within a hormetic framework. For example, an extensive field experiment also revealed that low concentrations of engineered Si nanoparticles alleviated negative effects of reduced watering on plant growth and leaf greenness, and increased yields in a hormetic manner (Alsaeedi et al., 2019). Nanomaterials may reduce or increase the accumulation of heavy metals by suppressing or enhancing the expression of transporter genes involved in heavy metal uptake and translocation (Yang et al., 2019).

Seed treatment and germination with nanoparticles/nanotubes can also induce hormesis in the emerged seedlings with priming/preconditioning (Savvides et al., 2016) at low concentrations persisting during the post-emergence seedling growth (Choudhary et al., 2019; Hong et al., 2005; Li et al., 2019; López-Moreno et al., 2010a,b; Ma et al., 2010; Razzaq et al., 2016; Taran et al., 2016; Tiwari et al., 2014). A statistical analysis conducted in this study indicated that seed soaking can induce as large or larger MAX than root or foliage treatment but optimum stimulation may be achieved when combined with vegetative treatments (root and foliage) (Taran et al., 2016); however, this may depend on the duration the seed preconditioning effect can persist.

Plants and algae can transform nanoparticles, thus, changing bioavailability and the thereby effects (López-Moreno et al., 2010a). This organismic property, and the direct effects of nanomaterials on the growing media and surfaces, highlight the need to understand if the preconditioning by low concentrations is due to real organismic stress response or a stimulation resulting indirectly, such as due to changes in the bioavailability of nutrients in the growing media.

When a type of $300 \mathrm{~nm} \quad \mathrm{TiO}_{2}$ nanoparticles (surface area $=11.5 \mathrm{~m}^{2} \mathrm{~g}^{-1}$ ) was tested in algae, it decreased toxicity of dissolved Cd(II) species, which was due to decreased bioavailability of Cd as a result of sorption/complexation of $\mathrm{Cd}^{2+}$ ions to the $\mathrm{TiO}_{2}$ surface. However, one type of $30 \mathrm{~nm} \quad \mathrm{TiO}_{2}$ nanoparticles (surface area $=47 \mathrm{~m}^{2} \mathrm{~g}^{-1}$ ) increased toxicity of dissolved Cd(II) species, suggesting a combined effect of $\mathrm{Cd}$ and $\mathrm{TiO}_{2}$ nanoparticles and/or that $\mathrm{TiO}_{2}$ increased the bioavailability of $\mathrm{Cd}$, i.e. carrier effect (Hartmann 
et al., 2010). The carrier effect depends on the cell wall. For instance, a study showed that carboxyl-CdSe/ZnS quantum dots decreased $\mathrm{Pb}$ and $\mathrm{Cu}$ intracellular content in walled strains, whose main cell wall component is glycoproteins, but highly increased $\mathrm{Pb}$ and $\mathrm{Cu}$ intracellular content in wall-less strains of green microalgae (Worms et al., 2012). These suggest that nanoparticles-induced protection against other stressors is not only due to classical biological preconditioning but also due to chemical engineering phenomena (e.g. chemical aggregation, metal corrosion, sorption of ions).

Studies with plant preconditioning also showed changes in the nutrient availability, uptake or accumulation. For instance, low concentrations of nanomaterials reduced arsenic-induced toxicity in two varieties of rice, but $\mathrm{Fe}_{3} \mathrm{O}_{4}$ and $\mathrm{Fe}$ nanomaterials prevented better the transportation of arsenic to the aboveground parts than $\mathrm{CxO}\left(\mathrm{H}_{2} \mathrm{O}\right)$ y and $\mathrm{Ca}_{10}\left(\mathrm{PO}_{4}\right)_{6}(\mathrm{OH})_{2}$ nanomaterials (Huang et al., 2018). In another experiment, $\mathrm{Si}$ nanoparticles increased $\mathrm{N}, \mathrm{K}$, and $\mathrm{Si}$ uptake in all plant tissues and decreased Na uptake in root, stem, and leaves of cucumber plants; all the nutrient contents and $\mathrm{K} / \mathrm{Na}$ ratio displayed a hormeticlike dose-response relationship (Alsaeedi et al., 2019). Similarly, experiments with barley seeds soaked with $\mathrm{MnFe}_{2} \mathrm{O}_{4}$ or $\mathrm{NiFe}_{2} \mathrm{O}_{4}$ nanoparticles and then grown in an $\mathrm{MnFe}_{2} \mathrm{O}_{4}$ or $\mathrm{NiFe}_{2} \mathrm{O}_{4}$ nanoparticle-containing hydroponic system revealed that low concentrations inducing stimulatory effects increased the leaf $\mathrm{Mn}$ or $\mathrm{Ni}$ and $\mathrm{Fe}$ contents too (Tombuloglu et al., 2018). Furthermore, in an experiment with soybean germinated seeds, the low concentration of $\mathrm{ZnO}$ nanoparticles that stimulated root elongation showed also lower agglomeration (and higher $\mathrm{Zn}$ concentration in the tissues) than higher concentrations with inhibitory effects, accompanied with higher availability of nanoparticles and Zn ions (López-Moreno et al., 2010a). These suggest that at least some of the response can be induced by elemental changes in both algae and plants. Changes in the elemental content in the tissues may be due to changes in the ionome which result from released ions from the nanomaterials. To this end, the recently expanding field of ionomics, and especially study of ionome-genome interactions, can provide further insights in the future (Watanabe et al., 2015, 2016). Hormesis-based applications of nanoparticles, with slow release of ions, on plants may be optimized based on preceding tests with major plant diseases at certain environments (Choudhary et al., 2019).

\subsection{Hormesis mechanisms}

As explained, one possible mechanism for hormesis could be changes in nutrient status. Low concentrations of nanomaterials can increase or decrease the content of micro- and macro-nutrients in plant tissues (Bello-Bello et al., 2017; López-Moreno et al., 2016; SpinosoCastillo et al., 2017; Tiwari et al., 2014; Tombuloglu et al., 2018, 2019; Wang et al., 2019; Xie et al., 2019). Elemental release from the nanomaterials can lead to accumulation of the released elements in the plant tissues (Tombuloglu et al., 2018, 2019; Wang et al., 2013). In fact, metal corrosion from the nanomaterials can increase the release of metals/ions, which may act as a main driver for the nanoparticles-induced toxicities (indirect effect) (Miao et al., 2009; Zhu et al., 2017; Bello-Bello et al., 2018). The amount of metal leaching from the nanoparticles should be considered because high release of ions may induce conversion of cellular $\mathrm{O}_{2}$ metabolic products (e.g. $\mathrm{H}_{2} \mathrm{O}_{2}$ and $\mathrm{O}-{ }_{2}$ ) into $\cdot \mathrm{OH}$ and thus cause genotoxicity (López-Moreno et al., 2010a; Singh et al., 2009). However, studies showed that this is not commonly the case as for example when magnetite $\left(\mathrm{Fe}_{3} \mathrm{O}_{4}\right)$ and maghemite $(\gamma$ $\mathrm{Fe}_{2} \mathrm{O}_{3}$ ) types of iron oxide nanoparticles at low concentrations enhanced muskmelon fruit fresh mass and fruit vitamin $\mathrm{C}$ without increasing significantly the $\mathrm{Fe}$ content in leaves, stem, root and fruit (Wang et al., 2019). Toxicological testing of the effects of dissolved ions, at amounts equal to the ions dissolved from applied high nanoparticles concentrations that caused inhibitory effects in wheat (Triticum aestivum L.) and rape (B. napus L.), also revealed no significant effect of released ions per se (Ma et al., 2010). These suggest that elements/ions released from nanomaterials are not a major driver of hormesis, although there can be potential ion exchange (e.g. via $\mathrm{Ca}-\mathrm{Fe}$ interactions) in the cell wall matrix (Tiwari et al., 2014).

The low-concentration enhancement can improve the photochemical reactions of photosystem II and induce notable changes in the nonphotochemical quenching (NPQ) in a time-concentration-response continuum (Mykhaylenko and Zolotareva, 2017; Malea et al., 2019). For example, CuZn bimetallic nanoparticles induced hormetic responses in the photosystem II (PSII) functionality of tomato plants, under high light $\left(900 \mu \mathrm{mol}\right.$ photons $\left.\mathrm{m}^{-2} \mathrm{~s}^{-1}\right)$, where reduction status of the plastoquinone pool (qP), relative PSII electron transport rate (ETR) and NPQ showed similar spatiotemporal responses (Antonoglou et al., 2018; see also Malea et al., 2019). Nanoparticles were also found to promote photophosphorylation activity of chloroplasts, related to both PSII and PSI, in a hormetic manner (Hong et al., 2005). Low concentrations of nanoparticles can enhance the chloroplast Hill reaction activity, accelerating $\mathrm{FeCy}$ reduction and $\mathrm{O}_{2}$ evolution (might enter the chloroplasts). Nanoparticles may have a direct effect on the $\mathrm{O}_{2}$-evolving complex, by increasing the permeability of the thylakoid membranes, hence enabling $\mathrm{Ca}^{2+}$ and $\mathrm{Cl}^{-}$enter the $\mathrm{O}_{2}$-evolving complex center easier, as well as by changing the combining position and state of $\mathrm{Ca}^{2+}$ and $\mathrm{Cl}^{-}$and protein structure in the $\mathrm{O}_{2}$-evolving complex (Hong et al., 2005). In addition to these light-related responses, research with algae revealed a potential direct shading effect by encapsulation of the cells (Hartmann et al., 2010); shading can also reduce the amount of light reaching the tissue surface (Hjorth et al., 2016), suggesting some potential protection against photoinhibition in environments with excess light (Kitao et al., 2000; Moustaka et al., 2018). Possible mechanisms for shading include adhesion of particles/aggregates to algal cell surface, physical effects (e.g. disruption of the cell membranes), and reduction of cellular nutrient uptake (Gong et al., 2011; Hartmann et al., 2010).

Hormetic response of photosynthetic pigments and carbohydrate and protein levels were found in different plants and for different nanomaterials (Choudhary et al., 2019; Razzaq et al., 2016; Salama, 2012; Tombuloglu et al., 2019). For example, increased biomass production by low concentrations of nanoparticles was accompanied with alike increases in the catalase activity and chlorophyll content in the leaf (Tombuloglu et al., 2018). Similarly, hormetic response was found in $\mathrm{H}_{2} \mathrm{O}_{2}$ content, and antioxidant (superoxide dismutase (SOD) and peroxidase (POD)) and defense (phenylalanine ammonia lyase and polyphenol oxidase) enzymes activities (Choudhary et al., 2019), as well as for total phenolic content and antioxidant capacity (Bello-Bello et al., 2017; Spinoso-Castillo et al., 2017). However, the latter hormetic responses were accompanied by linear response of ROS, which suggests that increase in ROS (and perhaps lipid peroxidation) up to a certain level stimulates while further increase inhibits plant functions (BelloBello et al., 2017; Spinoso-Castillo et al., 2017). Low concentrations of nanoparticles that can significantly increase photosynthetic pigments levels, protein contents, plant growth rate and biomass, may simultaneously decrease MDA production (Venkatachalam et al., 2017). MDA, proline and $\mathrm{H}_{2} \mathrm{O}_{2}$ contents displayed U-shape dose-response relationships in other studies with nanoparticles too (Manickavasagam et al., 2019), indicating a mechanism for reducing oxidative lipid injury. Furthermore, the low-concentration enhancement seems to relate to glutathione reductase (GR) and ascorbate peroxidase (APX) activities (anticorrelation), which are associated in the Halliwell-Asada cycle, where NAPDH and reduced glutathione (GSH) aid in restoring the reduced ascorbate pool (Morelli et al., 2012). APX and GR activities seem to also associate with catalase activity in the low-concentration zone (Morelli et al., 2012)

Although assessments of the physiological mechanisms underpinning nanomaterials-induced hormesis are becoming increasingly available, their links to genes are too limited. Among several miRNAs analyzed in switchgrass plants (Panicum virgatum L.), only some showed hormetic-like responses whose low-concentration responses were 
quantitatively similar to those of growth and production traits (Boykov et al., 2019). A research with Arabidopsis also revealed that low concentrations of $\mathrm{Ag}$ nanoparticles could alter the expression of genes regulating cellular pathways, such as proliferation, photosynthesis and hormone signaling, including auxin, abscisic acid, and ethylene (Syu et al., 2014). Accumulation of ROS and the proteins cell-division-cycle kinase 2 (CDC2), protochlorophyllide oxidoreductase (POR), and fructose-1,6 bisphosphate aldolase (FBA) and expression of the genes indoleacetic acid protein 8 (IAA8), 9-cis-epoxycarotenoid dioxygenase (NCED3), and dehydration-responsive RD22, were major mechanisms underpinning the low-concentration stimulation in Arabidopsis (Syu et al., 2014). Furthermore, chitosan nanoparticles induced hormesis in chlorophyll and soluble protein content, biomasses, R/S ratio, seeds germination of wheat (Li et al., 2019). This stimulation was upon upregulation of indole-3-acetic acid (IAA) synthetic genes and downregulation of metabolic genes (Li et al., 2019). In a recent study, Ag nanoparticles induced inverse $U$-shape concentration-response relationships in callus induction frequency, regeneration frequency, root length and number of roots and U-shape concentration-response relationships in MDA, $\mathrm{H}_{2} \mathrm{O}_{2}$ and proline content of regenerating calli of indica rice (Oryza sativa L.), with significant responses at both low and high concentrations along the full concentration-response spectrum (Manickavasagam et al., 2019). Similar U-shape concentration-response relationships were revealed for ERF063, OsRab16, OsIAA1, RR2, and $P B Z 1$, which are ethylene, abscisic acid, auxin, cytokinin, and gibberellic acid responsive genes, respectively. Although the responses to low concentrations were statistically non-significant, our analysis suggests that the responses of these genes are significantly correlated with the responses of root length across the concentration-response spectrum (Supplementary materials, Section 4), suggesting they associate with hormesis via decreasing or increasing expression levels. Regarding algae, the data of an extensive study with Phaeodactylum tricornutum Bohlin suggest that there were no apparent hormetic-like biphasic concentration-response relationships in the mRNA level of 10 genes (cox3, atpA, nad5, sufS, IscU, psaB, petF, $r b c \mathrm{~L}, p s b \mathrm{D}$, and $f t s \mathrm{H}) 48 \mathrm{~h}$ after the exposure (Zhu et al., 2017). However, cox3, atpA, nad5, psaB, and pet $\mathrm{F}$ showed a hormetic-like response with increased mRNA levels at $10 \mu \mathrm{M} \mathrm{Cu}$ nanoparticles, which was significantly different compared to the control particularly for nad5, $96 \mathrm{~h}$ after exposure. For cox3 (encodes the cytochrome $c$ oxidase subunit), nad5 (encodes the NADH dehydrogenase subunit), and petF (encodes in the photosystem reaction centers), there was a significant decline in the mRNA level around or below the control levels at $40 \mu \mathrm{M} \mathrm{Cu}$ nanoparticles (Zhu et al., 2017). cox3, atpA and nad5 encode proteins associated with the respiratory electron transport chain, whereas $p s a \mathrm{~B}$ and pet $\mathrm{F}$ encode proteins associated with photosynthesis electron transport chain, and such responses associated with hormetic-like responses observed in photosynthetic pigments as well. The different responses of these genes to lower and higher concentrations of nanoparticles suggest that they may be target for further research for hormesis drivers, this should be studied as a function of time as the responses differed over time. However, other genes (or the same but earlier) showed linear increases or decreases in the mRNA levels (Zhu et al., 2017), indicating that small increases or decreases may associate with low-level stimulation whereas high increase or decrease may associate with high-level inhibition. Further omic studies are need.

Nanoparticles may also affect plants indirectly by effecting the microbial community in the rhizo- or phyllo-sphere, something which remains to be studied.

\subsection{Relevance to humans}

Zn-chitosan nanoparticles increased the $\mathrm{Zn}$ content in maize (Zea mays L.) grain linearly with increasing $\mathrm{Zn}$-chitosan nanoparticles concentration, protected against disease, and caused significant enhancement of grain yields at low concentrations (Choudhary et al., 2019).
Other studies showed that Ag nanoparticles induced hormesis in the yields of wheat, with significant increases at low concentrations and inhibition at high concentrations; in one of the studies this was accompanied with enhanced N, P and K use efficiency (Jhanzab et al., 2015; Razzaq et al., 2016). ZnO nanoparticles given as foliar sprays also induced hormesis in field-cultivated dry bean (Phaseolus vulgaris L.) (Salama et al., 2019). Low concentrations enhanced plant growth, seed yields, shoot residues, the total energy for seeds, amino acids content, and micro- and macro-elements content in leaves and seeds; unique proteins at molecular weight $78 \mathrm{KDa}$ were found in response to the concentration at which the maximum stimulatory responses commonly occurred (Salama et al., 2019). These suggest that nanomaterials can induce hormesis in yields, with a potential for increasing agricultural products for human and animal consumption (Choudhary et al., 2019; Razzaq et al., 2016; Salama et al., 2019; Wang et al., 2019). However, low concentrations of nanomaterials can also increase or decrease the content of minerals that are important for human nutrition (e.g. increase fruit vitamin C (Wang et al., 2019)), depending on the plant tissue and element, which may change the ratio between elements (Alsaeedi et al., 2019; López-Moreno et al., 2016; Xie et al., 2019). This would entail implications to human nutrition and health. For this reason, the stoichiometry of agricultural products should be studied after applications of low concentrated nanomaterials.

The tissue-specific accumulation of elements released from nanoparticles in plant tissues, when nanoparticles applied at low concentrations for phytostimulation, should be further studied and understood in relation with humans and animals who potentially consume such agricultural products (Iavicoli et al., 2014; Wang et al., 2013). As nanomaterials induce hormesis in pathogens too, consumption of agricultural products with low concentration or content of nanomaterials may stimulate infectious pathogens, such as some strains of Escherichia coli, increasing the public risk, especially for sensitive populations facing heightened risks from infectious pathogens (Iavicoli et al., 2018; Xiu et al., 2012). Therefore, future studies should address potential risk within a nanomaterial-plant/environment-animal framework.

The World Health Organization (WHO) International Program on Chemical Safety (IPCS), the United Nations Environment Program (UNEP) and the International Labor Organization (ILO) publish jointly the Concise International Chemical Assessment Documents (CICADS), primarily concerned with the characterization of chemical hazard and dose-response. Future revisions of the CICADS should consider nanoparticle-induced hormetic dose responses in relation to human health and the environment (e.g. for Ag; World Health Organization, 2002).

\section{Conclusions}

Hormesis was widely induced by nanomaterials in plants and animals. Although hormesis appeared to vary among experimental conditions, MAX commonly constrained below two-fold the control response, indicating that nanomaterial-induced hormesis is constrained by the limits of biological plasticity.

This study suggests that seed soaking with nanomaterials may be utilized as a potential medium for seed priming with effective induction of maximum stimulatory responses. Seed soaking with nanomaterials may provide an important perspective for agricultural applicability to precondition plants before field cultivation. This practice may reduce the nanomaterials residuals in the environment if less field applications would be needed at vegetative stages.

The herein analysis also suggests that foliar application is not more effective than root application in inducing MAX, and that particles $\geq 100 \mathrm{~nm}$ may be safer for application into the environment than particles $\leq 50 \mathrm{~nm}$. Furthermore, it indicates that application of nanoparticles into a soilless growing medium, such as hydroponic culture, can induce similar MAX as when applied onto soil. While this provides a perspective for application to hydroponic cultures, chemical 
composition of resulting agricultural products should be assessed to account for potential risks from consumption.

The elemental release from particles does not seem to be the major mechanism for stimulation by low concentrations of nanomaterials. The understandings of the physiological mechanisms underlying hormesis are increasing; however, omic analyses within a concentration-timeresponse continuum are lacking. Future studies should examine how other factors may influence the concentration-response relationships such as particle size, aggregation, heteroaggregation, aggregate structure, shape, surface functionalization, crystallinity, metal concentration and stabilizer.

Hormesis should be considered in the nanomaterials risk assessment procedures, and potential risks by low-concentration responses should be taken into account.

\section{Funding}

E.A. and ZZ.F. acknowledge multi-year support from The Startup Foundation for Introducing Talent of Nanjing University of Information Science \& Technology (NUIST), Nanjing, China (No. 1411021901008 to E.A. and No. 002992 to ZZ.F.). E.J.C. acknowledges longtime support from the US Air Force (AFOSR FA9550-13-1-0047) and ExxonMobil Foundation (S18200000000256). The U.S. Government is authorized to reproduce and distribute for governmental purposes notwithstanding any copyright notation thereon. The views and conclusions contained herein are those of the authors and should not be interpreted as necessarily representing policies or endorsement, either expressed or implied. Sponsors had no involvement in study design, collection, analysis, interpretation, writing and decision to and where to submit for publication consideration. Authors declare that there is no conflict of interest.

\section{Author contributions}

Design of the study, literature survey and review, data extraction and handling, and initial drafting of the manuscript were done by E.A. Critical revisions of the manuscript for important intellectual content were performed by ZZ.F., I.I. and E.J.C. Each author has read and approved the final manuscript.

\section{Declaration of Competing Interest}

We wish to confirm that there are no known conflicts of interest associated with this publication and there has been no significant financial support for this work that could have influenced its outcome.

\section{Appendix A. Supplementary data}

Supplementary data to this article can be found online at https:// doi.org/10.1016/j.envint.2019.105044.

\section{References}

Agathokleous, E., Calabrese, E.J., 2019. Hormesis can enhance agricultural sustainability in a changing world. Glob. Food Sec. 20, 150-155. https://doi.org/10.1016/j.gfs. 2019.02.005.

Agathokleous, E., Araminiene, V., Belz, R.G., Calatayud, V., De Marco, A., Domingos, M., Feng, Z., Hoshika, Y., Kitao, M., Koike, T., Paoletti, E., Saitanis, C.J., Sicard, P., Calabrese, E.J., 2019a. A quantitative assessment of hormetic responses of plants to ozone. Environ. Res. 176, 108527. https://doi.org/10.1016/j.envres.2019.108527.

Agathokleous, E., Kitao, M., Calabrese, E.J., 2019b. Hormesis: a compelling platform for sophisticated plant science. Trends Plant Sci. 24, 24-37. https://doi.org/10.1016/j. tplants.2019.01.004.

Agathokleous, E., Kitao, M., Calabrese, E.J., 2019c. Hormetic dose responses induced by lanthanum in plants. Environ. Pollut. 244, 332-341. https://doi.org/10.1016/j. envpol.2018.10.007.

Alidoust, D., Isoda, A., 2013. Effect of $\gamma \mathrm{Fe}_{2} \mathrm{O}_{3}$ nanoparticles on photosynthetic characteristic of soybean (Glycine $\max$ (L.) Merr.): foliar spray versus soil amendment. Acta Physiol. Plant. 35, 3365-3375. https://doi.org/10.1007/s11738-013-1369-8.
Alidoust, D., Isoda, A., 2014. Phytotoxicity assessment of $\gamma-\mathrm{Fe}_{2} \mathrm{O}_{3}$ nanoparticles on root elongation and growth of rice plant. Environ. Earth Sci. 71, 5173-5182. https://doi. org/10.1007/s12665-013-2920-z.

Alsaeedi, A., El-Ramady, H., Alshaal, T., El-Garawany, M., Elhawat, N., Al-Otaibi, A., 2019. Silica nanoparticles boost growth and productivity of cucumber under water deficit and salinity stresses by balancing nutrients uptake. Plant Physiol. Biochem. 139, 1-10. https://doi.org/10.1016/j.plaphy.2019.03.008.

Antonoglou, O., Moustaka, J., Adamakis, I.D., Sperdouli, I., Pantazaki, A.A., Moustakas, M., Dendrinou-Samara, C., 2018. Nanobrass CuZn nanoparticles as foliar spray non phytotoxic fungicides. ACS Appl. Mater. Interfaces 10, 4450-4461. https://doi.org/ 10.1021/acsami.7b17017.

Auta, H.S., Emenike, C., Fauziah, S., 2017. Distribution and importance of microplastics in the marine environment: a review of the sources, fate, effects, and potential solutions. Environ. Int. 102, 165-176. https://doi.org/10.1016/j.envint.2017.02.013.

Bello-Bello, J.J., Chavez-Santoscoy, R.A., Lecona-Guzmán, C.A., Bogdanchikova, N., Salinas-Ruíz, J., Gómez-Merino, F.C., Pestryakov, A., 2017. Hormetic response by silver nanoparticles on in vitro multiplication of sugarcane (Saccharum spp. cv. Mex 69-290) using a temporary immersion system. Dose-Response 15, 155932581774494. https://doi.org/10.1177/1559325817744945

Bello-Bello, J.J., Spinoso-Castillo, J.L., Arano-Avalos, S., Martínez-Estrada, E., ArellanoGarcía, M.E., Pestryakov, A., Toledano-Magaña, Y., García-Ramos, J.C., Bogdanchikova, N., 2018. Cytotoxic, genotoxic, and polymorphism effects on Vanilla planifolia Jacks ex Andrews after long-term exposure to Argovit ${ }^{\circledR}$ silver nanoparticles. Nanomaterials 8, 754. https://doi.org/10.3390/nano8100754.

Belz, R.G., Duke, Stephen O., 2017. Herbicide-mediated hormesis. In: Duke, S.O., Kudsk, P., Solomon, K. (Eds.), Pesticide Dose: Effects on the Environment and Target and Non-target Organisms. American Chemical Society, Washington, pp. 135-148. https://doi.org/10.1021/bk-2017-1249.ch010.

Boykov, I.N., Shuford, E., Zhang, B., 2019. Nanoparticle titanium dioxide affects the growth and microRNA expression of switchgrass (Panicum virgatum). Genomics 111, 450-456. https://doi.org/10.1016/j.ygeno.2018.03.002.

Calabrese, E.J., 2014. Hormesis: a fundamental concept in biology. Microb. Cell 1, 145-149,. https://doi.org/10.15698/mic2014.05.145.

Calabrese, E.J., Blain, R.B., 2009. Hormesis and plant biology. Environ. Pollut. 157, 42-48. https://doi.org/10.1016/j.envpol.2008.07.028.

Calabrese, E.J., Howe, K.J., 1976. Stimulation of growth of peppermint (Mentha piperita) by phosfon, a growth retardant. Physiol. Plant. 37, 163-165. https://doi.org/10. 1111/j.1399-3054.1976.tb03951.x.

Carbery, M., O'Connor, W., Palanisami, T., 2018. Trophic transfer of microplastics and mixed contaminants in the marine food web and implications for human health. Environ. Int. 115, 400-409. https://doi.org/10.1016/j. envint.2018.03.007.

Chen, M., Zhou, S., Zhu, Y., Sun, Y., Zeng, G., Yang, C., Xu, P., Yan, M., Liu, Z., Zhang, W., 2018. Toxicity of carbon nanomaterials to plants, animals and microbes: recent progress from 2015-present. Chemosphere 206, 255-264. https://doi.org/10.1016/j. chemosphere.2018.05.020.

Choudhary, R.C., Kumaraswamy, R.V., Kumari, S., Sharma, S.S., Pal, A., Raliya, R., Biswas, P., Saharan, V., 2019. Zinc encapsulated chitosan nanoparticle to promote maize crop yield. Int. J. Biol. Macromol. 127, 126-135. https://doi.org/10.1016/j. ijbiomac.2018.12.274.

Chutipaijit, S., Sutjaritvorakul, T., 2017. Application of nanomaterials in plant regeneration of rice (Oryza sativa L.). Mater. Today Proc. 4, 6140-6145. https://doi. org/10.1016/j.matpr.2017.06.107.

Cocozza, C., Perone, A., Giordano, C., Salvatici, M.C., Pignattelli, S., Raio, A., Schaub, M., Sever, K., Innes, J.L., Tognetti, R., Cherubini, P., 2019. Silver nanoparticles enter the tree stem faster through leaves than through roots. Tree Physiol. https://doi.org/10. 1093/treephys/tpz046.

Cota-Ruiz, K., Delgado-Rios, M., Martínez-Martínez, A., Núñez-Gastelum, J.A., PeraltaVidea, J.R., Gardea-Torresdey, J.L., 2018. Current findings on terrestrial plants engineered nanomaterial interactions: are plants capable of phytoremediating nanomaterials from soil? Curr. Opin. Environ. Sci. Heal. 6, 9-15. https://doi.org/10 1016/j.coesh.2018.06.005.

Cutler, G.C., Guedes, R.N.C., 2017. Occurrence and significance of insecticide-induced hormesis in insects. In: Pesticide Dose: Effects on the Environment and Target and Non-target Organisms (ed. by Duke, S.O., Kudsk, P., Solomon, K.), ACS Publications, pp. 101-119. doi:https://doi.org/10.1021/bk-2017-1249.ch008.

Cutler, G.C., Rix, R.R., 2015. Can poisons stimulate bees? Appreciating the potential of hormesis in bee-pesticide research. Pest Manag. Sci. 71, 1368-1370. https://doi.org/ 10.1002/ps.4042.

Freixa, A., Acuña, V., Sanchís, J., Farré, M., Barceló, D., Sabater, S., 2018. Ecotoxicological effects of carbon based nanomaterials in aquatic organisms. Sci. Total Environ. 619-620, 328-337. https://doi.org/10.1016/j.scitotenv.2017.11.095.

Gong, N., Shao, K., Feng, W., Lin, Z., Liang, C., Sun, Y., 2011. Biotoxicity of nickel oxide nanoparticles and bio-remediation by microalgae Chlorella vulgaris. Chemosphere 83 510-516. https://doi.org/10.1016/j.chemosphere.2010.12.059.

Hartmann, N.B., Von der Kammer, F., Hofmann, T., Baalousha, M., Ottofuelling, S., Baun, A., 2010. Algal testing of titanium dioxide nanoparticles-testing considerations, inhibitory effects and modification of cadmium bioavailability. Toxicology 269 , 190-197. https://doi.org/10.1016/j.tox.2009.08.008.

Hjorth, R., Sørensen, S., Olsson, M.E., Baun, A., Hartmann, N.B., 2016. A certain shade of green: can algal pigments reveal shading effects of nanoparticles? Integr. Environ. Assess. Manag. 12, 200-202. https://doi.org/10.1002/ieam.1728.

Hong, F., Zhou, J., Liu, C., Yang, F., Wu, C., Zheng, L., Yang, P., 2005. Effect of nano-TiO on photochemical reaction of chloroplasts of spinach. Biol. Trace Elem. Res. 105, 269-280. https://doi.org/10.1385/bter:105:1-3:269.

Huang, Q., Liu, Q., Lin, L., Li, F.-J., Han, Y., Song, Z.-G., 2018. Reduction of arsenic toxicity in two rice cultivar seedlings by different nanoparticles. Ecotoxicol. Environ. 
Saf. 159, 261-271. https://doi.org/10.1016/j.ecoenv.2018.05.008.

Iavicoli, I., Calabrese, E.J., Nascarella, M.A., 2010. Exposure to nanoparticles and hormesis. Dose-Response 8, 501-517. https://doi.org/10.2203/dose-response.10 016.Iavicoli.

Iavicoli, I., Fontana, L., Leso, V., Calabrese, E.J., 2014. Hormetic dose-responses in nanotechnology studies. Sci. Total Environ. 487, 361-374. https://doi.org/10.1016/j scitotenv.2014.04.023.

Iavicoli, I., Leso, V., Beezhold, D.H., Shvedova, A.A., 2017. Nanotechnology in agriculture: opportunities, toxicological implications, and occupational risks. Toxicol. Appl. Pharmacol. 329, 96-111. https://doi.org/10.1016/j.taap.2017.05.025.

Iavicoli, I., Leso, V., Fontana, L., Calabrese, E.J., 2018. Nanoparticle exposure and hormetic dose-responses: an update. Int. J. Mol. Sci. 19, 805. https://doi.org/10.3390/ ijms19030805.

Jhanzab, H.M., Razzaq, A., Jilani, G., Rehman, A., Hafeez, A., Yasmeen, F., 2015. Silver nano-particles enhance the growth, yield and nutrient use efficiency of wheat. Int. J. Agron. Agric. Res. 7, 15-22.

Ji, J., Long, Z., Lin, D., 2011. Toxicity of oxide nanoparticles to the green algae Chlorella sp. Chem. Eng. J. 170, 525-530. https://doi.org/10.1016/j.cej.2010.11.026.

Kabir, E., Kumar, V., Kim, K.-H., Yip, A.C.K., Sohn, J.R., 2018. Environmental impacts of nanomaterials. J. Environ. Manag. 225, 261-271. https://doi.org/10.1016/j. jenvman.2018.07.087.

Kitao, M., Lei, T.T., Koike, T., Tobita, H., Maruyama, Y., 2000. Susceptibility to photoinhibition of three deciduous broadleaf tree species with different successional traits raised under various light regimes. Plant, Cell Environ. Cell Environ. 23, 81-89. https://doi.org/10.1046/j.1365-3040.2000.00528.x.

Kumar, S., Nehra, M., Dilbaghi, N., Marrazza, G., Hassan, A.A., Kim, K.-H., 2019. Nanobased smart pesticide formulations: emerging opportunities for agriculture. J. Control. Release 294, 131-153. https://doi.org/10.1016/j.jconrel.2018.12.012.

Li, R., He, J., Xie, H., Wang, W., Bose, S.K., Sun, Y., Hu, J., Yin, H., 2019. Effects of chitosan nanoparticles on seed germination and seedling growth of wheat (Triticum aestivum L.). Int. J. Biol. Macromol. 126, 91-100. https://doi.org/10.1016/j. ijbiomac.2018.12.118.

Lin, D., Xing, B., 2007. Phytotoxicity of nanoparticles: inhibition of seed germination and root growth. Environ. Pollut. 150, 243-250. https://doi.org/10.1016/j.envpol.2007. 01.016 .

López-Moreno, M.L., de la Rosa, G., Hernández-Viezcas, J.A., Castillo-Michel, H., Botez, C.E., Peralta-Videa, J.R., Gardea-Torresdey, J.L., 2010a. Evidence of the differential biotransformation and genotoxicity of $\mathrm{ZnO}$ and $\mathrm{CeO}_{2}$ nanoparticles on soybean (Glycine $\max$ ) plants. Environ. Sci. Technol. 44, 7315-7320. https://doi.org/10. 1021/es903891g.

López-Moreno, M.L., de la Rosa, G., Hernández-Viezcas, J.A., Peralta-Videa, J.R., GardeaTorresdey, J.L., 2010b. X-ray absorption spectroscopy (XAS) corroboration of the uptake and storage of $\mathrm{CeO}_{2}$ nanoparticles and assessment of their differential toxicity in four edible plant species. J. Agric. Food Chem. 58, 3689-3693. https://doi.org/10. 1021/jf904472e.

López-Moreno, M.L., Avilés, L.L., Pérez, N.G., Irizarry, B.Á., Perales, O., Cedeno-Mattei, Y., Román, F., 2016. Effect of cobalt ferrite $\left(\mathrm{CoFe}_{2} \mathrm{O}_{4}\right)$ nanoparticles on the growth and development of Lycopersicon lycopersicum (tomato plants). Sci. Total Environ. 550, 45-52. https://doi.org/10.1016/j.scitotenv.2016.01.063.

Ma, Y., Kuang, L., He, X., Bai, W., Ding, Y., Zhang, Z., Zhao, Y., Chai, Z., 2010. Effects of rare earth oxide nanoparticles on root elongation of plants. Chemosphere 78, 273-279. https://doi.org/10.1016/j.chemosphere.2009.10.050.

Malea, P., Charitonidou, K., Sperdouli, I., Mylona, Z., Moustakas, M., 2019. Zinc uptake, photosynthetic efficiency and oxidative stress in the seagrass Cymodocea nodosa exposed to ZnO nanoparticles. Materials 12, 2101. https://doi.org/10.3390/ ma12132101.

Manickavasagam, M., Pavan, G., Vasudevan, V., 2019. A comprehensive study of the hormetic influence of biosynthesized AgNPs on regenerating rice calli of indica cv. IR64. Sci. Rep. 9, 8821. https://doi.org/10.1038/s41598-019-45214-y.

Miao, A.-J., Schwehr, K.A., Xu, C., Zhang, S.-J., Luo, Z., Quigg, A., Santschi, P.H., 2009 The algal toxicity of silver engineered nanoparticles and detoxification by exopolymeric substances. Environ. Pollut. 157, 3034-3041. https://doi.org/10.1016/j. envpol.2009.05.047.

Morelli, E., Cioni, P., Posarelli, M., Gabellieri, E., 2012. Chemical stability of CdSe quantum dots in seawater and their effects on a marine microalga. Aquat. Toxicol. 122-123, 153-162. https://doi.org/10.1016/j.aquatox.2012.06.012.

Morelli, E., Salvadori, E., Bizzarri, R., Cioni, P., Gabellieri, E., 2013. Interaction of CdSe/ ZnS quantum dots with the marine diatom Phaeodactylum tricornutum and the green alga Dunaliella tertiolecta: a biophysical approach. Biophys. Chem. 182, 4-10. https:// doi.org/10.1016/j.bpc.2013.06.007.

Moustaka, J., Ouzounidou, G., Sperdouli, I., Moustakas, M., 2018. Photosystem II is more sensitive than photosystem I to $\mathrm{Al}^{3+}$ induced phytotoxicity. Materials (Basel) 11 1772. https://doi.org/10.3390/ma11091772.

Mykhaylenko, N.F., Zolotareva, E.K., 2017. The effect of copper and selenium nanocarboxylates on biomass accumulation and photosynthetic energy transduction efficiency of the green algae Chlorella vulgaris. Nanoscale Res. Lett. 12, 147. https://doi. org/10.1186/s11671-017-1914-2.

Navarro, E., Baun, A., Behra, R., Hartmann, N.B., Filser, J., Miao, A.-J., Quigg, A., Santschi, P.H., Sigg, L., 2008. Environmental behavior and ecotoxicity of engineered nanoparticles to algae, plants, and fungi. Ecotoxicology 17, 372-386. https://doi. org/10.1007/s10646-008-0214-0.

Poschenrieder, C., Cabot, C., Martos, S., Gallego, B., Barceló, J., 2013. Do toxic ions induce hormesis in plants? Plant Sci. 212, 15-25. https://doi.org/10.1016/j.plantsci. 2013.07.012.

Rai, P.K., Kumar, V., Lee, S., Raza, N., Kim, K.-H., Ok, Y.S., Tsang, D.C.W., 2018. Nanoparticle-plant interaction: implications in energy, environment, and agriculture.
Environ. Int. 119, 1-19. https://doi.org/10.1016/j.envint.2018.06.012.

Razzaq, A., Ammara, R., Jhanzab, H.M., Mahmood, T., Hafeez, A., Hussain, S., 2016. A novel nanomaterial to enhance growth and yield of wheat. J. Nanosci. Technol. 2, 55-58.

Reddy Pullagurala, V.L., Adisa, I.O., Rawat, S., Kim, B., Barrios, A.C., Medina-Velo, I.A., Hernandez-Viezcas, J.A., Peralta-Videa, J.R., Gardea-Torresdey, J.L., 2018. Finding the conditions for the beneficial use of $\mathrm{ZnO}$ nanoparticles towards plants-a review. Environ. Pollut. 241, 1175-1181. https://doi.org/10.1016/j.envpol.2018.06.036.

Reddy, P.V.L., Hernandez-Viezcas, J.A., Peralta-Videa, J.R., Gardea-Torresdey, J.L., 2016. Lessons learned: are engineered nanomaterials toxic to terrestrial plants? Sci. Total Environ. 568, 470-479. https://doi.org/10.1016/j.scitotenv.2016.06.042.

Salama, H.M., 2012. Effects of silver nanoparticles in some crop plants, common bean (Phaseolus vulgaris L.) and corn (Zea mays L.). Int. Res. J. Biotechnol. 3, 190-197.

Salama, D.M., Osman, S.A., Abd El-Aziz, M.E., Abd Elwahed, M.S.A., Shaaban, E.A., 2019. Effect of zinc oxide nanoparticles on the growth, genomic DNA, production and the quality of common dry bean (Phaseolus vulgaris). Biocatal. Agric. Biotechnol. 18, 101083. https://doi.org/10.1016/j.bcab.2019.101083.

Sanchís, J., Farré, M., Barceló, D., 2012a. Nanoparticles in environmental waters, determination of. In: Encyclopedia of Analytical Chemistry. John Wiley \& Sons, Ltd, Chichester, UK. https://doi.org/10.1002/9780470027318.a9284.

Sanchís, J., Farré, M., Barceló, D., 2012b. Chapter 4 - analysis and fate of organic nanomaterials in environmental samples. Compr. Anal. Chem. 59, 131-168. https:// doi.org/10.1016/B978-0-444-56328-6.00004-9.

Savvides, A., Ali, S., Tester, M., Fotopoulos, V., 2016. Chemical priming of plants against multiple abiotic stresses: Mission possible? Trends Plant Sci. 21, 329-340. https:// doi.org/10.1016/j.tplants.2015.11.003.

Singh, N., Manshian, B., Jenkins, G.J.S., Griffiths, S.M., Williams, P.M., Maffeis, T.G.G., Wright, C.J., Doak, S.H., 2009. NanoGenotoxicology: the DNA damaging potential of engineered nanomaterials. Biomaterials 30, 3891-3914. https://doi.org/10.1016/j. biomaterials.2009.04.009.

Spinoso-Castillo, J.L., Chavez-Santoscoy, R.A., Bogdanchikova, N., Pérez-Sato, J.A., Morales-Ramos, V., Bello-Bello, J.J., 2017. Antimicrobial and hormetic effects of silver nanoparticles on in vitro regeneration of vanilla (Vanilla planifolia Jacks. ex Andrews) using a temporary immersion system. Plant Cell Tissue Organ Cult. 129, 195-207. https://doi.org/10.1007/s11240-017-1169-8.

Syu, Y., Hung, J.-H., Chen, J.C., Chuang, H., 2014. Impacts of size and shape of silver nanoparticles on Arabidopsis plant growth and gene expression. Plant Physiol. Biochem. 83, 57-64. https://doi.org/10.1016/j.plaphy.2014.07.010.

Taran, N., Batsmanova, L., Kovalenko, M., Okanenko, A., 2016. Impact of metal nanoform colloidal solution on the adaptive potential of plants. Nanoscale Res. Lett. 11, 89. https://doi.org/10.1186/s11671-016-1294-z.

Tiwari, D.K., Dasgupta-Schubert, N., Villaseñor Cendejas, L.M., Villegas, J., Carreto Montoya, L., Borjas García, S.E., 2014. Interfacing carbon nanotubes (CNT) with plants: enhancement of growth, water and ionic nutrient uptake in maize (Zea mays) and implications for nanoagriculture. Appl. Nanosci. 4, 577-591. https://doi.org/10. 1007/s13204-013-0236-7.

Tombuloglu, H., Tombuloglu, G., Slimani, Y., Ercan, I., Sozeri, H., Baykal, A., 2018. Impact of manganese ferrite $\left(\mathrm{MnFe}_{2} \mathrm{O}_{4}\right)$ nanoparticles on growth and magnetic character of barley (Hordeum vulgare L.). Environ. Pollut. 243, 872-881. https://doi. org/10.1016/j.envpol.2018.08.096.

Tombuloglu, H., Slimani, Y., Tombuloglu, G., Almessiere, M., Baykal, A., Ercan, I., Sozeri, H., 2019. Tracking of $\mathrm{NiFe}_{2} \mathrm{O}_{4}$ nanoparticles in barley (Hordeum vulgare L.) and their impact on plant growth, biomass, pigmentation, catalase activity, and mineral uptake. Environ. Nanotechnology, Monit. Manag. 11, 100223,. https://doi.org/10. 1016/j.enmm.2019.100223.

Venkatachalam, P., Priyanka, N., Manikandan, K., Ganeshbabu, I., Indiraarulselvi, P., Geetha, N., Muralikrishna, K., Bhattacharya, R.C., Tiwari, M., Sharma, N., Sahi, S.V., 2017. Enhanced plant growth promoting role of phycomolecules coated zinc oxide nanoparticles with P supplementation in cotton (Gossypium hirsutum L.). Plant Physiol. Biochem. 110, 118-127. https://doi.org/10.1016/j.plaphy.2016.09.004.

Verma, S.K., Das, A.K., Patel, M.K., Shah, A., Kumar, V., Gantait, S., 2018. Engineered nanomaterials for plant growth and development: a perspective analysis. Sci. Total Environ. 630, 1413-1435. https://doi.org/10.1016/j.scitotenv.2018.02.313.

Verma, S.K., Das, A.K., Gantait, S., Kumar, V., Gurel, E., 2019. Applications of carbon nanomaterials in the plant system: a perspective view on the pros and cons. Sci. Total Environ. 667, 485-499. https://doi.org/10.1016/j.scitotenv. 2019.02.409.

Wang, J., Koo, Y., Alexander, A., Yang, Y., Westerhof, S., Zhang, Q., Schnoor, J.L., Colvin, V.L., Braam, J., Alvarez, P.J.J., 2013. Phytostimulation of poplars and Arabidopsis exposed to silver nanoparticles and $\mathrm{Ag}^{+}$at sublethal concentrations. Environ. Sci. Technol. 47, 5442-5449. https://doi.org/10.1021/es4004334.

Wang, Y., Wang, S., Xu, M., Xiao, L., Dai, Z., Li, J., 2019. The impacts of $\gamma-\mathrm{Fe}_{2} \mathrm{O}_{3}$ and $\mathrm{Fe}_{3} \mathrm{O}_{4}$ nanoparticles on the physiology and fruit quality of muskmelon (Cucumis melo) plants. Environ. Pollut. 249, 1011-1018. https://doi.org/10.1016/j.envpol.2019.03. 119.

Warheit, D.B., Hoke, R.A., Finlay, C., Donner, E.M., Reed, K.L., Sayes, C.M., 2007. Development of a base set of toxicity tests using ultrafine $\mathrm{TiO}_{2}$ particles as a component of nanoparticle risk management. Toxicol. Lett. 171, 99-110. https://doi.org/ 10.1016/j.toxlet.2007.04.008.

Watanabe, T., Urayama, M., Shinano, T., Okada, R., Osaki, M., 2015. Application of ionomics to plant and soil in fields under long-term fertilizer trials. Springerplus 4, 781 https://doi.org/10.1186/s40064-015-1562-x.

Watanabe, T., Maejima, E., Yoshimura, T., Urayama, M., Yamauchi, A., Owadano, M., Okada, R., Osaki, M., Kanayama, Y., Shinano, T., 2016. The ionomic study of vegetable crops. PLoS One 11, e0160273,. https://doi.org/10.1371/journal.pone. 0160273.

World Health Organization, 2002. Concise International Chemical Assessment Document 
44 - Silver and Silver Compounds: Environmental Aspects. World Health Organization, Geneva, pp. 37 ISBN 9241530448.

Worms, I.A.M., Boltzman, J., Garcia, M., Slaveykova, V.I., 2012. Cell-wall-dependent effect of carboxyl-CdSe/ZnS quantum dots on lead and copper availability to green microalgae. Environ. Pollut. 167, 27-33. https://doi.org/10.1016/j.envpol.2012.03. 030.

Xie, C., Ma, Y., Yang, J., Zhang, B., Luo, W., Feng, S., Zhang, J., Wang, G., He, X., Zhang, Z., 2019. Effects of foliar applications of ceria nanoparticles and $\mathrm{CeCl}_{3}$ on common bean (Phaseolus vulgaris). Environ. Pollut. 250, 530-536. https://doi.org/10.1016/j. envpol.2019.04.042.

Xiu, Z., Zhang, Q., Puppala, H.L., Colvin, V.L., Alvarez, P.J.J., 2012. Negligible particlespecific antibacterial activity of silver nanoparticles. Nano Lett. 12, 4271-4275. https://doi.org/10.1021/nl301934w.

Yang, H., Xu, Z., Liu, R., Xiong, Z., 2019. Lanthanum reduces the cadmium accumulation by suppressing expression of transporter genes involved in cadmium uptake and translocation in wheat. Plant Soil. https://doi.org/10.1007/s11104-019-04112-y.

Zheng, L., Hong, F., Lu, S., Liu, C., 2005. Effect of nano- $\mathrm{TiO}_{2}$ on strength of naturally aged seeds and growth of spinach. Biol. Trace Elem. Res. 104, 83-92. https://doi.org/10. 1385/bter:104:1:083.

Zhu, Y., Xu, J., Lu, T., Zhang, M., Ke, M., Fu, Z., Pan, X., Qian, H., 2017. A comparison of the effects of copper nanoparticles and copper sulfate on Phaeodactylum tricornutum physiology and transcription. Environ. Toxicol. Pharmacol. 56, 43-49. https://doi. org/10.1016/j.etap.2017.08.029. 